cambridge.org/ssr

\section{Editorial to the special issue on functional seed ecology}

Cite this article: Poschlod $P(2020)$. Let us have a functional view of seeds! A special Issue on "Functional Seed Ecology". Seed Science Research 30, 235-237. https://doi.org/10.1017/ S0960258521000027

\title{
Let us have a functional view of seeds! A special Issue on "Functional Seed Ecology"
}

\section{Peter Poschlod}

Chair of Ecology and Conservation Biology, Institute of Plant Sciences, Faculty of Biology and Preclinical Medicine, University of Regensburg, Universitaetsstrasse 31, D-93053 Regensburg, Germany

This Special Issue on Functional Seed Ecology is a follow-up of the Seed Ecology VI conference in 2019 in Regensburg, Germany. This meeting was organized by the Ecology and Conservation Biology working group at the Institute of Plant Sciences. Several papers were collected from this conference but some recent submitted papers associated to this topic were added.

A functional view on seeds should take different seed ecological aspects into account either related to germination or dispersal in space and time since they may explain a plant species distribution or local occurrence or even the species assembly in plant communities (Poschlod et al., 2013) or even the frequency or threat of a plant species (Murray et al., 2002; Römermann et al., 2008; see Fig. 1). Therefore, since recently, functional seed traits attract more and more attention in plant and vegetation ecology (e.g. Jimenez-Alfaro et al., 2016; Saatkamp et al., 2019). However, also conservation biology shows an increasing interest in seed functional traits which are related to a plant's population viability (Menges 2000), to conservation or restoration management (Bakker et al. 1996; Kahmen \& Poschlod 2008) or to the ex-situ storage of seeds (Probert et al., 2009; see Fig. 1).

This Special Issue contains 10 plus one papers. This one paper was designated for this issue but erroneously published already in the last issue of SSR (Astuti et al., Seed Science Research $30,45-48)$.

The papers cover various approaches of functional seed ecology but may be assorted to three sections covering the following aspects - first, dormancy and germination characteristics were studied to understand why single or several different species have a specific distribution or may prefer certain habitat niches. Second, functional aspects in ex-situ conservation by seed banking and how restoration and third, experimental approaches on seed dispersal.

Astuti et al. studied the speed of embryo development and germination in two closely related Tulipa species which differed only in the ploidy level. The embryo developed and seeds germinated much faster in the tetraploid Tulipa sylvestris in contrast to the diploid $T$. pumila which could explain the much wider distribution (or larger frequency) of the first in contrast to the second species. It would be interesting to see if this pattern occurs in other species with different ploidy levels.

Kallow et al. studied the germination requirements of the most important banana crop wild relative, Musa acuminata. Three subspecies were tested which all occur in disturbed sites of the tropical and sub-tropical Asian and Pacific rainforests. They all showed requirements to fluctuating temperatures explaining to detect the gaps in the rain forests.

Ranno et al. asked if differences in temperature and water potential thresholds for germination may explain the occurrence of the frequent and widespread Betula pendula and of two rare Mediterranean endemic birches, namley Betula aetnensis and Betula fontqueri. There were clear adaptations, especially in the drough tolerance. The two Mediterannean species germinated at a more negative water potential (= drier conditions).

Two papers were related to the effect of hypoxic conditions (prior) to germination. Echeverry Holguín et al. showed for the annual mudflat species Echinochloa crus-galli that hypoxic conditions are inhibiting germination if the dormancy of the seeds was broken or not, which can be interpreted as an avoidance mechanism to germinate under water.

Phartyal et al. studied five species typically occuring in mudflat habitats. Four of the five species germinated only at aerobic conditions. In one species low germination rates occurred at hypoxic conditions. However, after releasing the seeds from hypoxic conditions germination rates strongly increased in a species (and germination rates under aerobic conditions remained low) and decreased in another species which shows that hypoxic conditions may break or induce dormancy. Furthermore, in the three remaining species germination speed was strongy accelerated which is an interesting adaptation to these ephemeral habitats.

The last paper of this section is related to fire and germination. Dairel and Fidelis tested if temperature fluctuations and heat shock are able to overcome physiological dormancy in 10 native grasses of the most species-rich savannah of the world, the fire-prone Cerrado. Additionally, longevity after six and 12 months storage was tested, however, not under natural conditions which does not allow an interpretation of soil seed bank persistence. Three species 


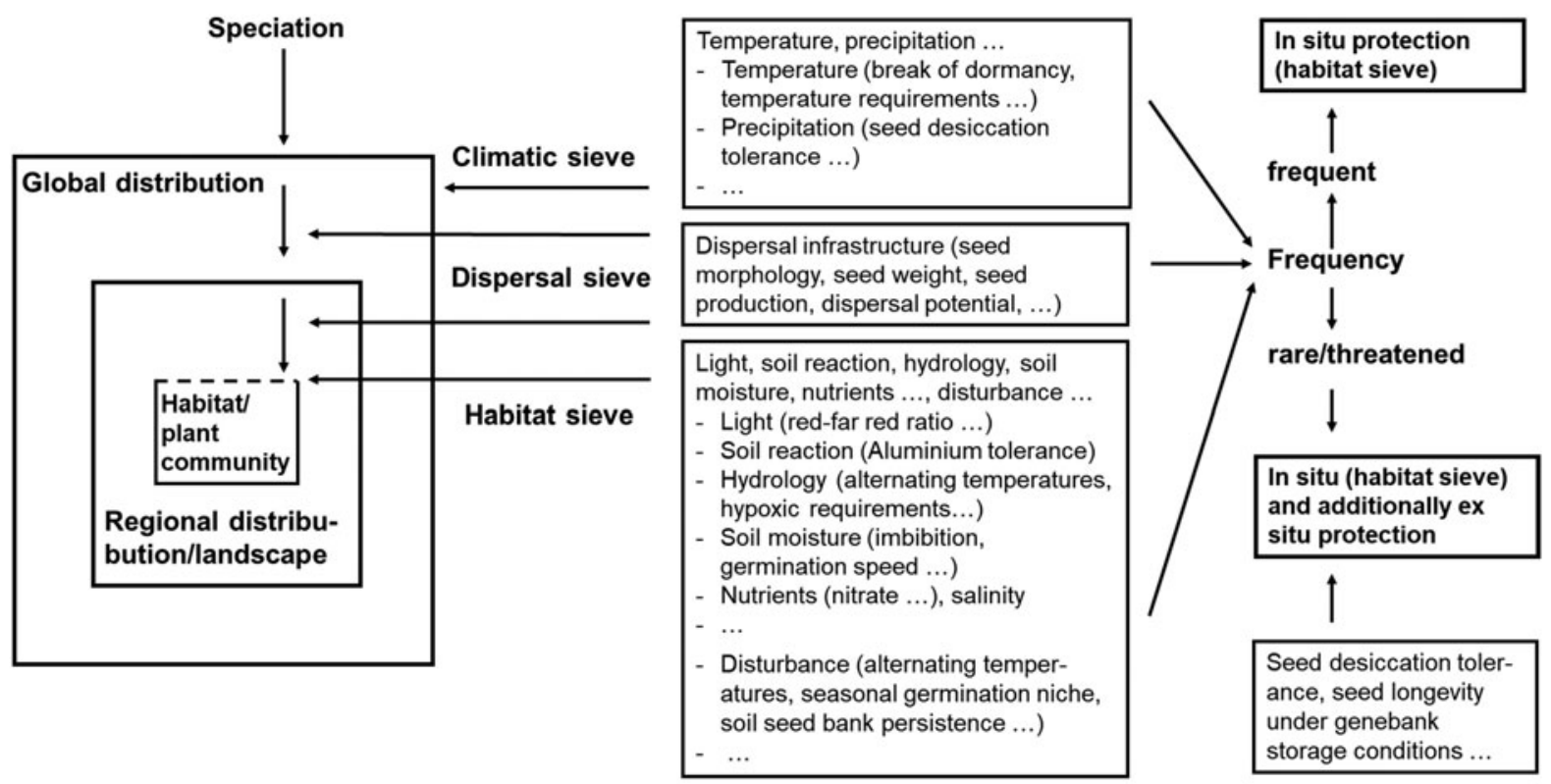

Fig. 1. Seed ecological traits affecting the distribution and the frequency of a plant species and plant species assembly (changed and supplemented after Poschlod et al. 2013).

had physiological dormancy. Germination percentage of the seeds of those species increased when exposed to temperature fluctuations. Heat shock did not increase germination percentage except a $200^{\circ} \mathrm{C}$ heat exposure in Sporobolus cubensis.

These six papers contribute to the increasing knowledge that there are germination ecological adaptations to climate and local habitat conditions. Furthermore, seed ecological traits may explain why certain species are more frequent and others rare. For the latter aspect, only common seed ecological traits such as seed mass and production were taken into account (e.g. Römermann et al., 2008).

Muthuthanthirige et al. tested with extensive experiments the occurrence of epicotyl morphophysiological dormancy and desiccation tolerance of seeds of three species of the tropical/subtropical genus Strychnos (Loganiaceae), two species growing in seasonally dry habitats but one in tropical rainforests. All three species are important medical plants and exhibited epicotyl morphophysiological dormancy. A strong adaptation to their habitats was found, however, in the speed of radicle and shoot emergence and desiccation tolerance. Radicle and shoot emergence lasted 30 days (or more) longer in the two species of the seasonally dry habitats than in the rainforest species. Seeds of the latter species were desiccation sensitive whereas seeds of the two other species were desiccation tolerant which has respective consequences for the ex situ storage.

Beveridge et al. applied different germination-enhancing chemicals and treatments with three different seed enhancement technologies to test the germination rate of three native Australian grass species on two different soil types. Whereas soil type did not influence emergence rates specific treatments did speeding up seedling emergence and increasing total emergence. Respective recommendations for restoration management are given.

The results of the first paper fit into the results of the first global biome related analysis of seed desiccation tolerance (Tweddle et al., 2003). The second contributes to an issue which was until now mainly taken into account for commercial seeds (horticulture, agriculture, forestry) but was strongly neglected in native species used in restoration practices (Paparella et al., 2015).

The last section containing three papers is related to dispersal. A methodological approach of how to catch seeds with seed traps is presented by Arruda et al.. They evaluated the effectiveness of two seed trap types (sticky and funnel traps) and the accuracy of a seed sorting method and proposed a standardized protocol which may allow in the future to better compare seed trap studies, an approach which was widely ignored in seed dispersal studies but should receive more attention.

The paper of Qin et al. covers the interesting aspect of how the vegetation structure may influence the dispersal kernel of wind dispersed seeds. Testing seeds of 29 species with different diaspore attributes, six interception canopy types and six wind speeds in controlled experiments they found out that diaspore attributes most strongly explained the interception rate after wind speed and canopy type. This aspect should, therefore, be more taken into account in future experiments or surveys when studying local plant distribution patterns or facilitation aspects (Levine and Murrell, 2003).

In the second paper of this section Amarasinghe et al. show in several specific experiments how important the barbed awn of wild rice spikelets/seeds in its natural habitat are for becoming detached, for the vertical fall to become squeezed to the ground but also to become dispersed horizontally on the ground or in water. This paper add more aspects to the biological significance of the role of awns (Cheplick, 1998).

All these papers confirm that seeds and a functional view on their ecology should no longer be ignored in plant and vegetation ecology but also restoration ecology and ex situ-conservation to better understand and protect our phytodiversity. For the future, however, we need more multispecies studies and meta analyses of certain or several seed ecological aspects along environmental or temporal (successional) gradients as shown by Kahmen et al. (2002), Tweddle et al. (2003), Fernandez-Pascual et al. (2020) 
and others. And we need more experiments to validate the functional patterns of these studies as shown by e.g. Kahmen and Poschlod (2008). These are the tasks we should aim for.

\section{References}

Bakker JP, Poschlod P, Strykstra RJ, Bekker RM and Thompson K (1996) Seed banks and seed dispersal: important topics in restoration ecology. Acta Botanica Neerlandica 45, 461-490.

Cheplick GP (1998) Seed dispersal and seedling establishment in grass populations, pp. 84-105 in Cheplick GP (Ed.) Population biology of grasses. Cambridge, UK: Cambridge University Press.

Fernández-Pascual E, Carta A, Mondoni A, Cavieres L, Rosbakh S, Venn S, Satyanti A, Guja L, Briceño V, Vandelook F, Mattana E, Saatkamp A, Bu H, Sommerville K, Poschlod P, Liu K, Nicotra A and Jiménez-Alfaro B (2020) The seed germination spectrum of alpine plants: a global meta-analysis. New Phytologist. https://doi-org.ezproxy.library.wur.nl/10.1111/nph.17086.

Jimenez-Alfaro B, Silveira FAO, Fidelis A, Poschlod P and Commander L (2016) Seed germination traits can contribute better to plant community ecology. Journal of Vegetation Science 27, 637-645. https://doi:10.1111/jvs.12375.

Kahmen S, Poschlod P and Schreiber KF (2002) Conservation management of calcareous grasslands. Changes in plant species composition and response of functional traits during 25 years. Biological Conservation 104, 319-328. https://doi.org/10.1016/S0006-3207(01)00197-5.

Kahmen S and Poschlod P (2008) Does germination success differ with respect to seed mass and germination season? Experimental testing of plant functional trait responses to grassland management. Annals of Botany 101, 541-548. https://doi.org/10.1093/aob/mcm311.

Levine JM and Murrell DJ (2003) The Community-Level Consequences of Seed Dispersal Patterns. Annual Review of Ecology, Evolution, and Systematics 34, 549-574.
Menges ES (2000) Population viability in plants: challenges and opportunities. Trends in Ecology and Evolution 15, 51-56. https://doi.org/10.1016/S01695347(99)01763-2.

Murray BR, Thrall PH, Gill AM and Nicotra AB (2002) How plant lifehistory and ecological traits relate to species rarity and commonness at varying spatial scales. Austral Ecology 27, 291-310. https://doi.org/10.1046/j. 1442-9993.2002.01181.x.

Paparella S, Araújo SS, Rossi G, Wijayasinghe M, Carbonera D and Balestrazzi A (2015) Seed priming: state of the art and new perspectives. Plant Cell Reports 34, 1281-1293. https:/doi:10.1007/s00299-015-1784-y

Poschlod P, Abedi M, Bartelheimer M, Drobnik J, Rosbakh S and Saatkamp A (2013) Seed ecology and assembly rules in plant communities, pp. 164-202 in van der Maarel E and Poschlod P, Abedi M, Bartelheimer M, Drobnik J, Rosbakh S and Saatkamp A Franklin J (Eds) Vegetation Ecology. 2nd. ed., Chichester, Wiley.

Probert RJ, Daws MI and Hay FR (2009) Ecological correlates of ex situ seed longevity: a comparative study on 195 species. Annals of Botany 104, 57-69. https://doi:10.1093/aob/mcp082

Römermann C, Tackenberg O, Jackel AK and Poschlod P (2008) Eutrophication and fragmentation are related to species' rate of decline but not to species rarity - Results from a functional approach. Biodiversity and Conservation 17, 591-604.

Saatkamp A, Cochrane A, Commander L, Guja LK, Jimenez-Alfaro B, Larson J, Nicotra A, Poschlod P, Silveira FAO, Cross AT, Dalziell EL, Dickie J, Erickson TE, Fidelis A, Fuchs A, Golos PJ, Hope M, Lewandrowski W, Merritt DJ, Miller BP, Miller RG, Offord CA, Ooi MKJ, Satyanti A, Sommerville KD, Tangney R, Tomlinson S, Turner S and Walck JL (2019) A research agenda for seed-trait functional ecology. New Phytologist 221, 1764-1775. https://doi:10.1111/nph.15502

Tweddle JC, Dickie JB, Baskin CC and Baskin JM (2003) Ecological aspects of seed desiccation sensitivity. Journal of Ecology 91, 294-304. https://doi:10. 1046/j.1365-2745.2003.00760.x 